\title{
PERAN GURU DALAM MENINGKATKAN KEDISIPLINAN BERIBADAH ANAK USIA DINI DI RA PERWANIDA DUSUN PUCANGOMBO KECAMATAN TEGALOMBO KABUPATEN PACITAN
}

\author{
Siti Nafiah \\ Institut Agama Islam Negeri Ponorogo \\ Email: nafiahsiti307@gmail.com \\ Evi Muafiah \\ Institut Agama Islam Negeri Ponorogo \\ Email: muafiahevi@gmail.com
}

\begin{abstract}
The objectives of this study are (1) to describe the discipline profile of early childhood worship in RA Perwanida, Pucangombo Hamlet, Tegalombo Pacitan; (2) to describe the role of the teacher as a guide in improving the discipline of early childhood worship at RA Perwanida, Pucangombo Hamlet, Tegalombo Pacitan; (3) to describe the teacher's role as a supervisor in improving the discipline of early childhood worship in RA Perwanida, Pucangombo Hamlet, Tegalombo Pacitan. This study uses a qualitative approach to the type of case study research. The results of this study are: (1) Discipline profile for children of age in RA Perwanida Pucangombo Hamlet Tegalombo Pacitan in general is included in the category of lack of discipline. (2) The role of the teacher as a guide, the teacher collaborates with parents of parents to take part in implementing / implementing regulations has been determined by the school institution in the sense that parents should support the child. 3) The role of the teacher as a supervisior, being a model / example in applying the discipline of worship to early childhood continuously, the teacher provides supervision
\end{abstract}

Keywords: Role of Teachers, Discipline of worship, early childhood

\begin{abstract}
Abstrak: Tujuan penelitian ini adalah (1) untuk mendeskripsikan profil kedisiplinan beribadah anak usia dini di RA Perwanida Dusun Pucangombo Tegalombo Pacitan; (2) untuk mendeksripsikan peran guru sebagai pembimbing dalam meningkatkan kedisiplinan beribadah anak usia dini di RA Perwanida Dusun Pucangombo Tegalombo Pacitan; (3) untuk mendeksripsikan peran guru sebagai supervisor dalam meningkatkan kedisiplinan beibadah anak usia dini di RA Perwanida Dusun Pucangombo Tegalombo Pacitan. Penelitian ini menggunakan pendekatan kualitatif dengan jenis penelitian studi kasus. Hasil penelitian ini adalah: (1) Profil kedisiplinan beribadah anak usia di RA Perwanida Dusun Pucangombo Tegalombo Pacitan secara umum termasuk dalam kategori kurang disiplin.(2) Peran guru sebagai pembimbing, Guru melakukan kerjasama dengan orangtua wali murid agar ikut menjalankan/menerapkan peraturan yang sudah ditentukan oleh lembaga sekolah dalam artian hendaknya orangtua mendukung anak. 3) Peran guru sebagai supervisior, menjadi model/contoh dalam menerapkan kedisiplinan beribadah terhadap anak usia dini secara terus menerus, Guru memberi pengawasan.
\end{abstract}

Kata Kunci: Peran Guru, Kedisiplinan beribadah, anak usia dini 


\section{PENDAHULUAN}

PAUD merupakan singkatan dari Pendidikan Anak Usia Dini. Pada undang-undang Sistem Pendidikan Nasional No. 20 Tahun 2003 bab 1 pasal 1 ayat 1 dijelaskan bahwa pendidikan adalah usaha sadar dan terencana untuk mewujudkan suasana belajar dan proses pembelajaran agar peserta didik secara aktif mengembangkan potensi dirinya untuk memiliki kekuatan spiritual kegamaan, pengendalian diri, kepribadian, kecerdasan, akhlak mulia serta keterampilan yang diperlukan dirinya, masyarakat, bangsa dan Negara. ${ }^{1}$ Sementara itu, anak data diartikan dengan individu yang belum dewasa. Sedangkan usia dini adalah rentang usia 0 hingga 6 tahun.

Jadi PAUD dapat diartikan sebagai usaha sadar dan terencana untuk mewujudkan suasana belajar dan proses pembelajaran kepada anak usia 0 hingga 6 tahun secara aktif dan kreatif agar memiliki kecerdasan emosional dan spiritual, serta kecerdasan intelektual yang diperlukan bagi dirinya, masyarakat, bangsa dan Negara. Mengacu pada kedua definisi di atas menunjukkan bahwa pendidikan sangat penting dan berguna bagi kemajuan dan perkembangan peserta didik, termasuk di dalamnya ialah disiplin.

Disiplin merupakan salah satu pendidikan karakter yang sangat penting untuk ditanamkan bagi anak usia dini sejak kecil. Dengan penanaman disiplin maka anak akan terbiasa melakukan kebaikan dan menaati/mematuhi aturan sesuai norma, nilai, tuntutan yang berlaku di lingkungan masyarakat sekitar anak. Menurut pakar psikologi, anak usia dini merupakan masa yang tepat untuk melakukan pendidikan, sebab, pada masa ini anak sedang mengalami proses pertumbuhan dan perkembangan yang luar biasa. Anak belum memiliki pengaruh negatif yang banyak dari luar atau lingkungannya sehingga orang tua maupun pendidik akan jauh lebih mudah dalam mengarahkan dan membimbing

${ }^{1}$ Novan Ardy Wiyani, Konsep Dasar PAUD, (Yogyakarta: Penerbit Gava Media, 2016), 1. 
anak-anaknya, terutama dalam penanaman nilai-nilai karakter yaitu disiplin. $^{2}$

Anak usia dini memiliki karakeristik yang khas, baik secara fisik, psikis, sosial, moral, spiritual maupun emosional. Anak usia dini merupakan masa yang paling tepat untuk membentuk fondasi dan dasar kepribadian yang akan menentukan pengalaman selanjutnya. Oleh karena itu, memahami anak usia dini merupakan sesuatu yang sangat penting bagi para orang tua, guru, pemerintah, dan masyarakat pada umumnya. Melalui pemahaman tersebut akan sangat membantu mengembangkan mereka secara optimal sehingga kelak menjadi generasi-generasi yang siap memasuki era globalisasi yang penuh dengan macam tantangan dan permasalahan yang semakin rumit dan kompleks. ${ }^{3}$

Usia dini merupakan usia yang paling tepat untuk membentuk perilaku keagamaan Islam pada anak. Anak usia dini antara 2-6 tahun adalah fase yang tepat untuk menanamkan nilai-nilai Islam. Penanaman mendidik perilaku kegamaan baru dimulai sejak dini karena dari usia dini itulah anak-anak harus memiliki pegangan akhlak yang baik. Dan AlQuran harus juga menjadikan pedoman dalam mendidik akhlak Islam dalam perilaku kegamaan bagi anak-anak. Jika hal ini dilakukan sejak dini oleh orang tua maka anak-anak akan memiliki jiwa rohaniah yang baik dan akan selalu taat dan patuh kepada perintah orang tua maupun perintah agama.

Tak terlepas pula dari peran guru, guru adalah bagian terpenting dalam dunia pendidikan, karena tanpa guru sulit atau bahkan tidak akan dapat dicapai tujuan pendidikan. Guru mempunyai tuntutan yang cukup berat jika kita hubungkan dengan tujuan pendidikan. Dalam hal akhlah guru bertanggung jawab membimbing dan dapat maenjadi contoh bagi peserta didik.

\footnotetext{
${ }^{2}$ Muhammad Fadlillah \& Lilif Mualifatu Khorida, Pendidikan Karakter Anak Usia Dini: Konsep \& Aplikasinya dalam PAUD, (Jogjakarta: Ar-Ruzz, 2014), 43.

${ }^{3}$ Mulyasa, .93
} 
Meskipun anak sudah diajari oleh orang tuanya dirumah, tapi peran guru sebagai pentransfer ilmu dan mendidik perilaku keagamaan anak sangatlah penting karena tidak semua orang tua memiliki pengetahuan yang luas dalam hal agama dan kebanyakan orang tua tidak memiliki waktu untuk mengajari anaknya. Jadi peran guru sangatlah penting tidak hanya di sekolah saja tapi juga diluar sekolah. Seorang guru tidak hanya memberikan pendidikan itu dalam bentuk materi saja, tetapi lebih dari itu harus dapat menyentuh sisi tauladannya. Sebab perilaku seorang gurulah yang pertama-tama dilihat siswanya. Seorang guru selain memberikan pendidikan yang bersifat materi pelajaran, juga harus memberikan contoh yang baik dalam sosialisasi kehidupan. Bagaimana murid akan berperilaku sesuai dengan yang diajarkan oleh gurunya, jika gurunya sendiri tidak pernah memberikan contoh yang baik terhadap anak didiknya.

ljazah S1 yang dimiliki oleh pendidik PAUD mempresentasikan atau setidaknya menjadi legalitas formal bahwa pendidik PAUD telah memiliki keahlian, kemahiran, dan kecakapan yang memenuhi standar Pendidikan Anak Usia Dini. Dengan keahlian, kemahiran, kecakapannya itulah pendidik PAUD menjadi pendidik profesional.Sebagai pendidik professional, pendidik PAUD idealnya berperan dalam mendidik, mengajar, membimbing, melatih, dan mengevaluasi peserta didiknya. ${ }^{4}$

Kedisiplinan dapat diajarkan kepada anak di sekolah maupun di rumah dengan cara membuat semacam peraturan atau tata tertib yang wajib dipatuhi oleh setiap anak. Peraturan dibuat secara fleksibel, tapi tegas. Dengan kata lain, peraturan menyesuaikan dengan kondisi perkembangan anak, serta dilaksanakan dengan penuh ketegasan. Apabila ada anak yang melanggar, harus menrima konsekuensi yang telah disepakati.Oleh karena itu, supaya peraturan dapat berjalan dengan baik, hendaknya orangtua maupun pendidik menyosialisasikan terlebih dahulu kepada anak-anak.

${ }^{4}$ Novan Ardy wiyani, Konsep Dasar Paud, (Yogyakarta: Gava Media, 2016).68 
Peraturan untuk menanamkan kedisiplinan dapat dilakukan mulai dari hal-hal yang sederhana, seperti menempatkan sepatu pada tempatnya, ketika makan minum, mandi atau yang lainnya anak dianjurkan berdoa terlebih dahulu dan membudayakan untuk antri, kemudian, yang tak kalah penting ialah perilaku disiplin ini harus pula ditunjukkan oleh orangtua maupun pendidik itu sendiri. Apabila kita menghendaki anak didik kita untuk disiplin, kita pun mesti menunjukkan sikap disiplin di hadapan anak-anak. ${ }^{5}$

Kita semua menyadari pentingnya disiplin dalam perkembangan dan penanaman moral anak.Konsep umum dari disiplin disamakan dengan hukuman.Konsep ini menyatakan bahwa disiplin digunakan jika anak melanggar aturan-aturan yang ditetapkan oleh orangtua, guru, maupun orang dewasa lainnya. Disiplin merupakan cara masyarakat mengajarkan anak berperilaku moral yang diterima oleh masyarakat.

Tujuan dari disiplin adalah membentuk perilaku yang sesuai dengan kelompok sosialnya. Walaupun demikian ada orangtua yang takut bahwa dengan menerapkan disiplin akan menimbulkan masalah dalam hubungan dengan anak-anaknya. Oleh karena itu, ada konsep yang bertentangan dengan disiplin itu sendiri. Konsep yang memandang disiplin sebagai konsep yang negatif, berarti sama dengan hukuman. Sedangkan konsep positif samadengan pendidikan, bimbingan dalam menetapkan disiplin diri, dan control diri. Disiplin adalah penting bagi perkembangan anak karena berisi hal-hal yang diperlukan anak. Disiplin akan menambah kebahagiaan, penyesuaian pribadi dan sosial mereka. ${ }^{6}$

\footnotetext{
${ }^{5}$ Muhammad Fadlillah \& Lilif Mualifatu Khorida, Pendidikan Karakter Anak Usia Dini: Konsep \& Aplikasinya dalam PAUD, (Jogjakarta: Ar-Ruzz Media, 2014) 192-193.

${ }^{6}$ Zubaedi, Strategi Taktis Pendidikan Karakter (Untuk PAUD dan Sekolah), (Depok: PT Raja Grafindo Persada, 2017)36.
} 


\section{METODE PENELITIAN}

Dalam penelitian ini yang digunakan adalah metode penelitian dengan pendekatan kualitatif.Dimana pengertian penelitian kualitatif adalah penelitian yang berangkat dari inkuiri naturalistik yang temuantemuannya tidak diperoleh dari produser penghitungan penghitungan secara statistik. ${ }^{7}$

Penelitian kualitatif melibatkan penggunaan dan pengumpulan berbagai bahan empiris (studi kasus, pengalaman pribadi, intropeksi, riwayat hidup, wawancara, pengamatan, teks sejarah, interaksi dan visual) yang menggambarkan momen rutin dan problematic, serta maknanya dalam kehidupan individual dan kolektif. Penelitian kualitatif adalah penelitian yang bermaksud untuk memahami fenomena tentang apa yang dialami oleh subyek penelitian (contohnya: perilaku, persepsi, motivasi, tindakan, dan sebagainya) secara holistik, dan dengan cara deskripsi dalam bentuk kata-kata dan bahasa, pada suatu konteks khusus yang alamiah dan dengan memanfaatkan berbagai metode alamiah. ${ }^{8}$

\section{HASIL DAN PEMBAHASAN}

Berkaitan dengan kedisiplinan, di RA Perwanida Dusun Pucangombo Tegalombo Pacitan anak usia dini termasuk dalam kategori baik. Kedisiplinan anak sudah berkembang sesuai harapan namun belum maksimal. Hal ini ditunjukkan dengan anak mulai patuh terhadap tuntutan atau peraturan, anak paham akan apa yang harus dilakukan sesuai dengan kegiatan rutinan yang dilakukan dengan bimbingan dan juga pengawasan dari guru, meskipun ada beberapa anak yang masih sulit dalam pelaksanaan kegiatan kedisiplinan.

\footnotetext{
${ }^{7}$ Basrowi \& Suwandi, Memahami Penelitian Kualitatif, (Jakarta: PT Rineka Cipta, 2008), 22.

${ }^{8}$ Andi Prastowo, Metode Penelitian Kualitatif Dalam Perspektif Rancangan Penelitian (Jogjakarta: AR-Ruzz Media, 2012), 23-24.
} 
Di dalam kedisiplinan dapat diketahui bahwa RA Perwanida juga mempunyai peraturan yang harus ditaati/dipatuhi untuk menunjang keberhasilan kegiatan yang ada.Seluruh kegiatan yang ada di RA Perwanida mewajibkan anak untuk tertib, disiplin dan terampil.Salah satu kegiatannya adalah pembiasaan pagi yang dilakukan untuk setiap harinya.Kegiatan tersebut tidak akan berjalan dengan apabila tidak adanya peraturan yang mengatur waktu di dalam pelaksanaan kegiatannya. Untuk itu agar semua berjalan lancar sesuai dengan yang diharapkan, pihak sekolah mengatur sebuah jadwal kegiatan.Dengan adanya sebuah jadwal yang diatur oleh pihak sekolah, diharapkan pihak sekolah mengatur sebuah jadwal kegiatan. Dengan adanya sebuah jadwal yang diatur oleh pihak sekolah, diharapkan menjadi solusi dan mampu meningkatkan kedisiplinan anak RA kelompok $A$ dan $B$ dalam berbagai kegiatan yang ada terutama dalam pembiasaan pagi.

Perilaku tidak disiplin yang dilakukan anak kelompok B dalam mengikuti kegiatan pembiasaan pagi bermacam-macam.Perilaku tidak disiplin tersebut seperti ramai sendiri dengan temannya, mengganggu temannya dengan mengajaknya berbicara, padahal sebisa mungkin semua guru berperan dalam kegiatan pembiasaan pagi tersebut.

Berbagai permasalahan kedisiplinan anak di dalam mengikuti kegiatan pembiasaan pagi tentunya sangat mempengaruhi terhadap keberhasilan anak di dalam mencari ilmu di sekolah. Keberhasilan itu tidak akan mereka raih kecuali mereka bisa berperilaku disiplin dalam mengikuti kegiatan pembiasaan pagi tersebut anak akan mendapatkan banyak tambahan pengetahuan. Tetapi apabila mereka tidak disiplin dalam mengikuti kegiatan pembiasaan pagi tentu mereka tidak akan mendapatkan banyak tambahan ilmu pengetahuan umum atau ilmu agama seperti menghafalkan beberapa do'a harian, surat-surat pendek, hadis sederhana, niat wudhu, niat dan praktek shalat, shalawat, mengaji iqra dan asmaul husna. 
RA Perwanida Dusun Pucangombo Tegalombo Pacitan juga memiliki jadwal kegiatan untuk mengatur semua anak kelompok $A$ maupun Kelompok B dalam mengikuti seluruh kegiatan yang ada, khususnya pembiasaan pagi (dimulai dari berbaris saat akan memasuki kelas, berdo'a bersama dan membaca ikrar). Kegiatan tersebut merupakan kegiatan yang diwajibkan untuk semua anak di RA Perwanida Dusun Pucangombo Tegalombo Pacitan.

\section{KESIMPULAN}

Berdasarkan hasil penelitian dengan judul "Peran guru dalam meningkatkan kedisiplinan beribadah anak usia dini di RA Perwanida Dusun Pucangombo Tegalombo Pacitan" adalah sebagai berikut:

1. Profil kedisiplinan beribadah anak usia di RA Perwanida Dusun Pucangombo Tegalombo Pacitan secara umum termasuk dalam kategori kurang disiplin. Hal ini ditunjukkan anak kurang mematuhi peraturan yang sudah ditetapkan oleh guru dengan bimbingan dan arahan dari guru.

2. Peran guru sebagai pembimbing dalam meningkatkan kedisiplinan beribadah anak usia dini di RA Perwanida Dusun Pucangombo Tegalombo Pacitan adalah sebagai berikut:

a. Guru melakukan kerjasama dengan orangtua wali murid agar ikut menjalankan/menerapkan peraturan yang sudah ditentukan oleh lembaga sekolah dalam artian hendaknya orangtua mendukung anak.

b. Guru memberikan teladan yang baik dalam berdisiplin agar anak dapat meniru dan menerapkan baik di lingkungan sekolah maupun di rumah.

c. Guru memberikan contoh langsung kepada anak pada setiap kegiatan, sehingga anak akan meniru apa yang mereka lihat. 
d. Guru membimbing, mengingatkan, mengarahkan, menjelaskan bahwa sikap disiplin itu penting dilakukan karena akan mempermudah sikap dan perilaku serta akan terbiasa bila sudah terbiasa disiplin.

3. Peran guru sebagai supervisor dalam meningkatkan kedisiplinan beribadah anak usia dini di RA Perwanida Dusun Pucangombo Tegalombo Pacitan adalah sebagai berikut:

a. Guru menjadi model/contoh dalam menerapkan kedisiplinan beribadah terhadap anak usia dini secara terus menerus.

b. Guru memberi pengawasan, pelatihan dan memperbaiki cara belajar atau bersikap anak agar terbiasa dalam penerapan sikap disiplin di sekolah maupun dirumah. Dari hal-hal yang kecil sudah ditanamkan hal-hal yang baik pada anak maka anak akan menjadi pribadi yang taat peraturan, memiliki karakter disiplin saat memasuki pendidikan dasar bahkan hingga dewasa kelak.

\section{DAFTAR PUSTAKA}

Wiyani, Novan Ardy. Konsep Dasar PAUD. Yogyakarta: PT. Gava Media, 2014.

M, Fadlillah, dkk. Pendidikan Karakter Anak Usia Dini:Konsep dan Aplikasinya. Jogjakarta: Ar Ruzz Media, 2014.

Mulyasa.Manajemen PAUD. Bandung: PT. Remaja Rosdakarya, 2016.

Zubaedi.Strategi Taktis Pendidikan Karakter (Untuk PAUD dan Sekolah). Depok: PT Raja Grafindo Persada, 2017.

Basrowi \& Suwandi. Memahami Penelitian Kualitatif. Jakarta: PT Rineka Cipta, 2008.

Prastowo, Andi. Metode Penelitian Kualitatif Dalam Perspektif Rancangan Penelitian. Jogjakarta: AR-RUZZ MEDIA, 2014. 